\title{
The Glasgow Asylum of 1810
}

\section{R.H.S. Mindham}

In the eighteenth century, the mentally ill of Glasgow were accommodated in the basement of the Town's 1733 Hospital in Clyde Street which was subject to flooding. The authorities engaged the young Scottish architect William Stark to prepare plans for a new hospital for the insane on a site to the North of the city.

Stark went about his task with great thoroughness, seeking the opinions of those with experience of mental illness and visiting existing hospitals in Montrose, Liverpool and Manchester. In London, Bethlem Hospital was preparing to move from Moorfields to Saint George's Fields, Lambeth but the plans were undecided. Saint Luke's Hospital for Lunatics, London was of a similar design to Bethlem. Stark was impressed by The Retreat in York which had been built by the Religious Society of Friends in 1796 following their dissatisfaction with the treatment of one of their number in the York County Lunatic Asylum. However, it was not the design of The Retreat which impressed Stark, but the approach to patient care employed there. This was based on Quaker beliefs as to how people should behave towards one another irrespective of sex, social standing or mental illness.

William Stark presented his report to a public meeting in 1807. He recommended the method of care adopted at The Retreat: " $t$ is a government of humanity and consummate skill, and requires no aid from the arm of violence, or exertions of brutal force'. He proposed a regimen of non-violence through careful observation and attention to patients. He believed that, in the atmosphere produced, patients would feel secure and that disturbance would be minimised.

In his design Stark was influenced by the writings of the philosopher Jeremy Bentham who, in 1787, proposed a principle of a building for the accommodation of persons who needed to be supervised which he named 'The Panopticon'. He foresaw his idea being applied to the building of prisons, factories, schools, hospitals and other settings. One of the first hospitals to be built on the panopticon principle was the 'Lunatic House' of 1797, created for 24 patients at Guy's Hospital, London. Stark planned a building to accommodate 126 patients who were to be separated according to sex, social class and degree of disturbance.

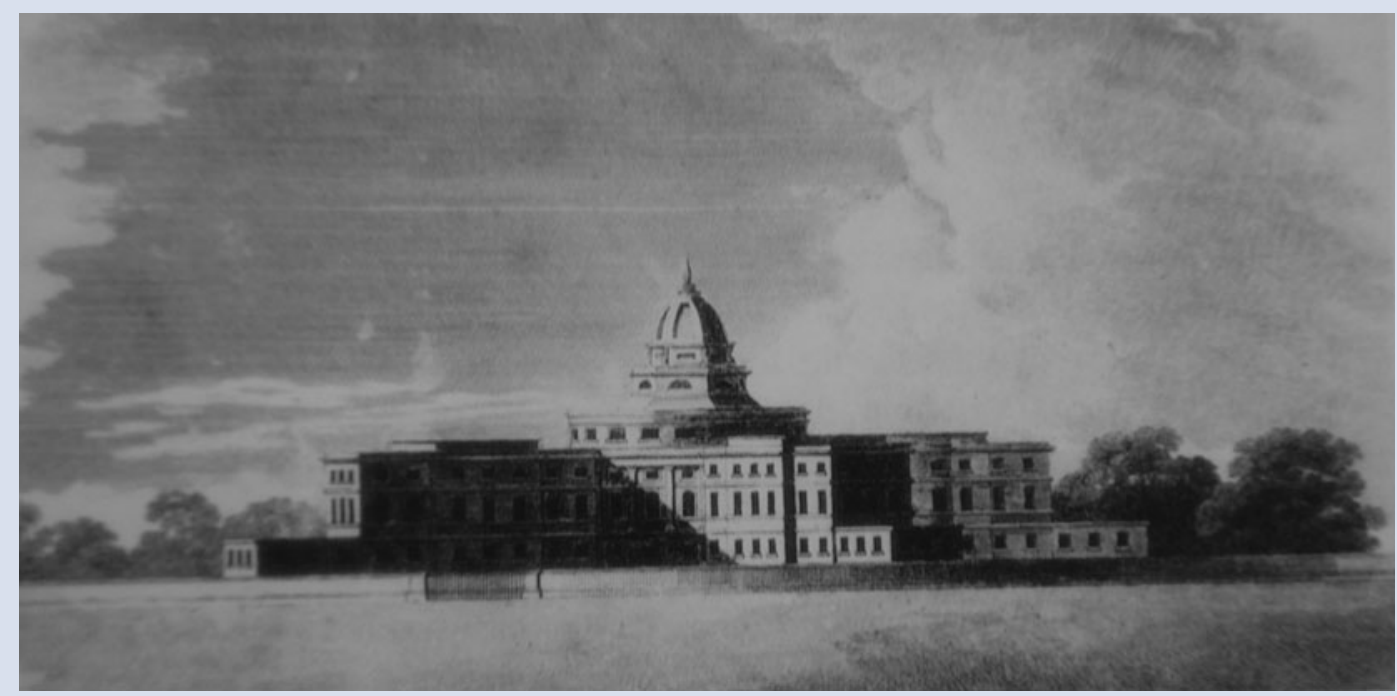

The engraving of the Glasgow Asylum is reproduced with permission of the Wellcome Library, London.

The architect proposed a cross-shaped building with each wing consisting of three stories. He adopted the gallery ward used by Hooke at Bethlem, in which single rooms and a wide corridor were set side by side. The gallery was used for recreation and as a corridor. At the centre of the building were day rooms and accommodation for staff. On each level there was a clear view of the gallery of each ward from a raised position, enabling senior staff to supervise patient care without themselves being seen. The building was surmounted by a dome which accommodated the chapel. The hospital was visible from many parts of the city and was easily identified by its unusual profile. The cross-shaped plan can be seen on many maps of the city. Contemporary commentators praise its appearance.

Stark demonstrated that the panopticon principle could be applied to the building of a large hospital for the insane. A number of hospitals were built on this model: Liff Hospital, Dundee by Stark (1812-20); the Gloucester Asylum by Stark and Collingwood (1813-23); the Cornwall County Asylum, Bodmin by Foulston (1818); the West Riding Asylum, Wakefield by Watson and Pritchett, advised by Samuel Tuke (1814-18); the Murray Royal Hospital, Perth (1822-7) and the Crichton Royal Hospital, Dumfries (1835-9), both by William Burn.

Problems with the model soon emerged: the arrangements for observation allowed noise, dirt and infection to spread around the buildings and the use of single rooms was too expensive. Moreover the principles of care used at The Retreat required unattainable numbers of experienced staff. The panopticon went out of favour, but Stark had established a model for the planning of hospitals, the standards of which have rarely been exceeded.

Copyright (c) The Royal College of Psychiatrists 2019 